1 Universidade de Santa Cruz do Sul (Unisc).

Departamento de

Psicologia - Santa Cruz do

Sul (RS), Brasil.

moisesromanini@unisc.br

2 Universidade Federal

do Rio Grande do Sul

(UFRGS), Programa

de Pós-Graduação

em Psicologia Social e

Institucional - Porto Alegre

(RS), Brasil.

pedrinho.guareschi@ufrgs.br

3 Universidade Federal de Santa Maria (UFSM),

Programa de Pós-

Graduação em Psicologia -

Santa Maria (RS), Brasil.

psicosocial.ufsm@gmail.com

\section{$O$ conceito de acolhimento em ato: reflexões a partir dos encontros com usuários e profissionais da rede}

The concept of user embracement in act: reflections from the meetings with users and professionals of the network

Moises Romanini', Pedrinho Arcides Guareschi2 ${ }^{2}$, Adriane Roso ${ }^{\mathbf{3}}$

RESUMO Este artigo tem como objetivo analisar e problematizar os sentidos atribuídos por profissionais e usuários da Rede de Atenção Psicossocial (Raps) de Porto Alegre/RS às práticas de acolhimento. A pesquisa está inserida no espectro das pesquisas participativas. Adotaram-se como estratégias metodológicas a observação participante, em três contextos da Raps da cidade de Porto Alegre, o diário de campo, as entrevistas narrativas (com usuários e profissionais) e os grupos de discussão com os profissionais. Inscrito em um regime de alteridade, o acolhimento se transforma em um encontro dialógico, sempre polifásico e marcado por tensões.

PALAVRAS-CHAVE Acolhimento. Serviços de saúde. Saúde mental. Psicologia social.

ABSTRACT This article aims to analyze and problematize the meanings attributed by professionals and users of the Network of Psychosocial Care (Raps) in Porto Alegre/RS to the user embracement practices. The research is inserted in the spectrum of participative researches. The participant observation, in three contexts of the Raps of the city of Porto Alegre, the field diary, the narrative interviews (with users and professionals) and the discussion groups with the professionals were adopted as methodological strategies. Inscribed in a regime of otherness, the embracement becomes a dialogical encounter, always polyphasic and marked by tensions.

KEYWORDS User embracement. Health services. Mental health. Social psychology. 


\section{Introdução}

Atualmente, nas discussões em torno das políticas sobre drogas, há uma urgência por internações de usuários de crack, uma urgência construída num determinado contexto de disputas políticas e ideológicas, sem que, com tal ponderação, desconsidere-se a necessidade de intervenções, bem como a gravidade do problema. Só que tal fato, respaldado pelo aumento expressivo de ordens judiciais para internação compulsória, bem como dos pedidos de familiares para internações involuntárias de usuários de drogas, remete ao difícil debate sobre o financiamento público das comunidades terapêuticas, que se fundamenta, em grande parte, em uma moral religiosa. O desinvestimento nos serviços públicos, característica importante do neoliberalismo, justifica a contratação de serviços privados, como as comunidades terapêuticas e as clínicas particulares (ROMANINI; DETONI, 2014).

Essa discussão aparece com força quando se fala sobre o uso de drogas. Há, ainda, um discurso difundido na sociedade de que os jovens usam drogas porque fazem parte de uma família 'desestruturada' ou, ao contrário, que a família se desestrutura em função de algum familiar que usa drogas. Geralmente, no primeiro caso, trata-se de famílias pobres 'causadoras' do uso. Entretanto, tais discursos desconsideram que a noção de família dissolvida ou desestruturada traz consigo o modelo de família burguesa oitocentista, e tudo o que foge desse padrão é considerado em desordem. Reside, portanto, nesses discursos, uma responsabilização e/ou culpabilização da dissolução da família pela situação de degradação social em que se vive, como se a crise social contemporânea não tivesse nenhuma relação com a degradação dos espaços públicos e de políticas sociais destinadas às camadas mais pobres da população (ROMANINI; ROSO, 2013).

Tanto a urgência das internações (involuntárias e compulsórias) quanto esses discursos que culpabilizam as famílias pelo uso de drogas podem ser considerados efeitos da lógica proibicionista que vem sustentando práticas no campo das políticas sobre drogas. $\mathrm{O}$ proibicionismo coloca a droga como inimigo a ser combatido pelas políticas públicas (principalmente de segurança), e a abstinência como único objetivo dos tratamentos ofertados. Em oposição à redução de danos, o discurso proibicionista sustenta o paradigma da abstinência, que, embora considere a recaída como parte do processo, coloca-a como um fracasso da meta de uma sociedade livre das drogas. Entretanto, por meio das reflexões de Souza e Carvalho (2012), percebe-se que a recaída não aparece como um fracasso das instituições que ofertam a assistência em saúde, mas como um fracasso individual, uma fraqueza do indivíduo, uma falha moral. Vê-se, portanto, que a abstinência como meta única, a dependência química como diagnóstico e a internação compulsória como medida de tratamento funcionam num círculo vicioso que individualiza o fracasso (souzA; CARVALHO, 2012), sustentando e reproduzindo o modo indivíduo de subjetivação nas políticas sobre drogas. O fracasso como tecnologia de subjetivação, tendo a culpabilização como seu principal efeito.

O modo indivíduo de subjetivação, atualizado nessas políticas, coloca sérias limitações à construção de políticas 'efetivamente' públicas, porque sustenta dicotomias, como indivíduo e sociedade, bem e mal, certo e errado, o abstinente e o fracassado. Por isso, a aposta na construção do comum é fundamental, enfatizando a dimensão pública de uma política. $\mathrm{O}$ comum implica a abertura ao outro - a questão da alteridade, a composição de singularidades, o acolhimento à multiplicidade, a capacidade de diferir -, a pluralidade, que constitui o plano político em Hannah Arendt (2010). Por isso, o comum sempre advém da experiência, é heterogêneo, acompanha práticas concretas e cria efeito de pertencimento - os encontros entre profissionais-gestores-usuários-pesquisador. Como afirmam Barros e Pimentel (2012), desestabilizam-se as fronteiras entre saberes e atores, ocorrendo o atravessamento de diferentes semióticas através da experiência da 
dimensão do coletivo. Coletivo como experiência do comum, potencializando saberes até então excluídos.

Diante desse contexto, parte-se do pressuposto de que o acolhimento pode ser considerado um dispositivo de construção do comum, concretizado nos encontros cotidianos entre profissionais e usuários. Sendo urgente o debate sobre as práticas de acolhimento a pessoas que usam drogas, uma vez que se percebe o avanço de práticas individualizadoras nesse campo, como a necessidade cada vez maior de internações compulsórias dos usuários. Entendendo que o acolhimento acontece no encontro, inscrito em fluxo de afetos e de saberes singulares (profissionais e usuários), este artigo tem como objetivo analisar e problematizar os sentidos atribuídos por profissionais e usuários da Rede de Atenção Psicossocial (Raps) de Porto Alegre (RS) às práticas de acolhimento. O presente artigo é um recorte da tese de doutorado do primeiro autor, intitulada 'Narrativas do Desassossego: do re-en-colhimento às práticas de acolhimento aos usuários de drogas na Rede de Atenção Psicossocial de Porto Alegre/RS'. O projeto de pesquisa foi aprovado pelos Comitês de Ética da Secretaria Municipal de Saúde de Porto Alegre e do Instituto de Psicologia da Universidade Federal do Rio Grande do Sul, sob CAAE no ${ }^{\circ}$ 26347613.7.3001.5338.

Apresenta-se neste manuscrito uma síntese dos debates realizados, ao longo de um ano, com usuários e profissionais da Área Técnica de Saúde Mental, de um Centro de Atenção Psicossocial Álcool e outras Drogas (Caps AD) e de uma equipe de Consultório na Rua (eCnR) do referido município.

\section{Metodologia}

Esta pesquisa está inserida no espectro das pesquisas participativas. Adotaram-se como estratégias metodológicas a observação participante, em três contextos da Raps da cidade de Porto Alegre (RS) (Área Técnica de Saúde Mental, Caps AD e Consultório na Rua-CnR), o diário de campo, as entrevistas narrativas (com usuários e profissionais) e os grupos de discussão com os profissionais. A pesquisa ocorreu entre 31 de março de 2014 e 02 de junho de 2015. Nesse período, foram concluídas 298 horas de observação participante em 86 imersões no campo de estudo. Além das observações, foram realizados três grupos de discussão e 34 entrevistas narrativas com usuários e profissionais dos serviços.

A pesquisa foi realizada junto à Raps da cidade de Porto Alegre, Rio Grande do Sul, Brasil. A inserção dos pesquisadores nessa Rede de Atenção aconteceu através de uma parceria estabelecida com a equipe de profissionais que compõem a Área Técnica (AT) de Saúde Mental da Secretaria Municipal de Saúde de Porto Alegre (SMSPA). Para tal, participaram de reuniões, encontros com profissionais da rede e visitas técnicas aos serviços, compondo com a área técnica de saúde mental. Outra 'porta de entrada' aos serviços observados foram os encontros do Fórum Álcool e outras Drogas (Fórum AD), através dos quais se reúnem profissionais de toda a Raps para estudar e discutir temas pertinentes às práticas e experiências profissionais dos envolvidos. À medida que esses espaços foram sendo ocupados, propôs-se a entrada em dois pontos de atenção da Raps, além das atividades desenvolvidas pela AT (como os Fóruns da Raps e Fórum AD). Dessa maneira, os interlocutores da pesquisa, inseridos em serviços da Raps, foram os profissionais da Área Técnica de Saúde Mental (e aqueles profissionais que participam dos encontros do Fórum $\mathrm{AD}$, atividade desenvolvida pela AT) e integrantes das equipes dos serviços, bem como usuários acessados pelas equipes ou que frequentam as atividades dos serviços acompanhados (Caps $\mathrm{AD}$ e $\mathrm{CnR}$ ), com um projeto terapêutico. Os interlocutores foram homens e mulheres, maiores de 18 anos.

Por fim, uma estratégia adotada foi a utilização de heterônimos. Essa estratégia é, ao mesmo tempo, teórico-metodológica e ética, 
no que tange à preservação do anonimato dos interlocutores. Assim como o título da tese da qual resulta este manuscrito, o uso dos heterônimos teve como fonte inspiradora o poeta Fernando Pessoa, conhecido, também, por utilizar amplamente heterônimos - entre os mais conhecidos, Alberto Caeiro, Álvaro de Campos, Ricardo Reis e Bernardo Soares. Tanto no caso da obra de Fernando Pessoa quanto no deste trabalho, os heterônimos fazem emergir uma concepção de sujeito cujas identidades são múltiplas, um sujeito que é atravessado por diversas e, muitas vezes, paradoxais identificações, resultando no desdobramento do 'eu', em seu descentramento em direção ao outro. Os nomes dos heterônimos foram fruto de associações livres e também de pesquisas. Pensou-se em uma série de pessoas, mais ou menos conhecidas publicamente, vinculadas ao mundo das artes, da literatura, do cinema, da saúde, da psicologia, do movimento da reforma psiquiátrica e de movimentos LGBTs (Lésbicas, Gays, Bissexuais, Travestis, Transexuais e Transgêneros) e feministas. O heterônimo foi apresentado com o nome e a primeira letra do sobrenome, seguido de ponto final.

\section{Resultados e discussão}

Dos inúmeros e marcantes encontros com profissionais e usuários do Caps $\mathrm{AD}$, do Consultório na Rua e dos profissionais que participaram do Fórum $\mathrm{AD}$, através da inserção junto à $\mathrm{AT}$, além dos encontros com os autores que discutem a noção de acolhimento (FRANCO; BUENO; MERHY, 1999; FRANCO; FRANCO, 2012; BRASIL, 2006, 2011; TEIXEIRA, 2003, 2004; NEVES; HECKERT, 2010; SCHMIDT; FIGUEIREDO, 2009; FRANCO; MERHY, 2013), propõe-se, agora, um movimento de retorno e síntese das diferentes formas de definir o acolhimento, tendo como base as observações, os grupos de discussão e as entrevistas realizadas no decorrer da pesquisa.

Nos três contextos observados (AT, Caps AD e CnR), vislumbra-se a noção de 'acolhimento como uma ação ou atividade'. Nessa forma de conceber o acolhimento, tem-se uma atividade de um profissional direcionada a um usuário que chega ao serviço. Mas essa atividade é feita de modos distintos, conforme o nível de formação do profissional. Trata-se de uma atividade de 'recepção', 'triagem' ou 'acolhimento inicial', quando é realizado por profissionais de nível básico ou técnico (principalmente, técnicos de enfermagem, agentes comunitários de saúde e profissionais de nível administrativo e serviços gerais), e de um 'procedimento técnico-especializado', quando realizado por profissionais de nível superior (médicos, enfermeiros, psicólogos, assistentes sociais, terapeutas ocupacionais, entre outros).

No primeiro caso, entende-se que o acolhimento acontece desde que o usuário entra no serviço, por isso, faz-se importante uma uniformidade das equipes no que se refere à forma como recebem esse usuário, pois se ele "for mal atendido" (Grupo de Discussão Fórum $\mathrm{AD}$ ), não volta mais ou "não adere ao tratamento" (Simone B.). Os serviços se organizam de forma a diferenciar as atividades: no Caps $\mathrm{AD}$, um longo debate sobre qual profissional está de fato capacitado para fazer uma "escuta qualificada" (Clarice L.); no CnR, as técnicas de enfermagem fazem a recepção, a triagem e, depois, encaminham para o "acolhimento dos médicos e enfermeiros” (Francisca G.). No segundo caso, os profissionais "não recebem apenas a pessoa, mas escutam a história, a doença, a dependência química” (Anita G.). Para escutar e trabalhar com tais elementos, os profissionais supõem que existam saberes necessários mínimos, que seriam ofertados ainda na formação universitária.

Nessa forma de conceber o acolhimento, espera-se dos profissionais uma "postura acolhedora"; o "bom profissional recebe com um sorriso no rosto" (Grupo de Discussão Fórum AD). Mas essa postura de alegria e de uma certa benevolência é mais exigida dos profissionais que fazem a triagem e a recepção, porque dos segundos, além disso ser tomado como algo natural, espera-se a 'técnica'. Essa concepção de acolhimento traz uma implicação importante aos processos de 
saúde: o usuário adere ou não adere ao tratamento proposto. Pois, se o profissional recebe bem o usuário, tem técnica para escutar sua história e para propor terapêuticas, e o usuário não volta, é porque este não tem a capacidade de aderir ao tratamento, ou em função de sua doença ou em virtude de características que demarcam a população atendida (no caso dos usuários de drogas, as recaídas são comuns, por isso eles vão e voltam, têm dificuldade em 'aderir'; no caso dos moradores de rua, eles são itinerantes, não se acostumam com regras, por isso não 'aderem').

A ideia de aderência está amplamente disseminada nos serviços. Durante esse ano de pesquisa, era muito comum escutar nos diferentes espaços que os usuários não 'aderem' ao tratamento ofertado. "Nós ofertamos o cuidado, eles não aderem”. $\mathrm{E}$ isso não apenas no contexto hospitalar, como apontaram alguns profissionais durante $o$ grupo de discussão junto ao Fórum $\mathrm{AD}$, mas nos Caps, no Consultório na Rua, nos encontros entre os diferentes serviços da rede, o termo aderência ganha relevo. A palavra aderência vem do latim adhaerentia, que significa ligação. Aderência é a qualidade ou o atributo do que é aderente. No campo da engenharia mecânica, pode-se dizer que aderência é a força de contato entre os pneus de um veículo e o solo, por exemplo. No campo da patologia, é a união fibrosa congênita ou acidental de superfícies orgânicas naturalmente contíguas. Em qualquer um dos significados, tem-se algo que adere, que se junta a outra coisa. Na saúde mental, então, quando se fala que os sujeitos aderem ou não aderem ao tratamento, implicitamente, quer-se dizer que o usuário pode ser classificado como tendo ou não tendo a qualidade de ser aderente.

Tal concepção parece estar intrinsecamente ligada à noção de acolhimento como uma ação ou atividade de um profissional. $\mathrm{Eu}$ acolho o outro, ofereço o 'menu' de atividades, grupos, atendimentos e oficinas do meu serviço, e o usuário adere ou não, participa ou não. A metáfora oferecida pela patologia é muito cara a nós nessa reflexão. Ao tratar da aderência como uma união fibrosa de superfícies orgânicas naturalmente contíguas, pode-se pensar nos dois sujeitos que se encontram na atividade do acolhimento (profissional e usuário) como duas 'superfícies orgânicas' que naturalmente se ligam, pois a existência de uma depende da existência da outra. A união ocorre naturalmente, já que o que o serviço oferece é aquilo de que o usuário necessita. Se ele não adere, é porque lhe falta $o$ atributo de ser aderente. A falta desse atributo é, geralmente, explicada pelas características da pessoa acometida pelo diagnóstico da dependência química - falta de motivação, a fissura, as recaídas, a dissimulação - ou por fatores entendidos como 'externos' - a 'desestrutura familiar', a pobreza, a falta de melhores condições de vida.

Ou seja, quando se lança mão da noção de aderência, reforça-se a ideia de que o acolhimento é uma atividade unidirecional - voltada ou direcionada de um profissional especializado para o usuário. Além disso, deposita-se sobre o sujeito-usuário a responsabilidade pelo 'fracasso' do tratamento, pois é ele quem não possui o atributo da aderência. Essa reflexão não tem como objetivo culpabilizar os profissionais, mas evidenciar o que está implícito nessa noção e o quanto ela pode ser perversa, individualizando ainda mais o problema no sujeito usuário da droga ou em sua família. Apesar dessa crítica, não se pode negar que o acolhimento se configura, na prática, como uma atividade dos profissionais, inclusive sendo contabilizada como produção de saúde no Registro de Ações Ambulatoriais em Saúde (Raas) - acolhimento noturno, acolhimento em $3^{\circ}$ turno, acolhimento diurno no Caps e acolhimento inicial.

É a esse acolhimento inicial, previsto como procedimento do Raas, que a maioria dos profissionais se refere quando fala do acolhimento como uma atividade. $\mathrm{O}$ acolhimento inicial é entendido como "talvez, o 
mais importante da pessoa, porque a pessoa está chegando ao serviço". Por isso,

o profissional tem uma responsabilidade muito grande neste momento, porque, dependendo de como for esse encontro com o outro, a gente tem, enfim, a gente pode causar coisas boas, coisas não tão boas assim... (Grupo de Discussão Fórum $A D)$.

Neste ponto do debate, há algo importante a ser destacado. Na fala citada, aparece uma noção de que a atividade do acolhimento vai além de um procedimento técnico-especializado ou de uma recepção. A ênfase na importância desse encontro é fundamental, pois evidencia a responsabilidade com o outro, com o usuário, e que o profissional pode causar 'coisas boas' ou 'coisas não tão boas assim'. Essas coisas boas e nem tão boas também podem ser sentidas pelos próprios profissionais, pois, como escreveu um dos participantes do grupo de discussão, "no ritmo do afeto, o olhar do acolhimento escapa à unilateralidade" (Grupo de Discussão Fórum AD). Ao olhar intensamente, somos olhados. O acolhimento, dessa maneira, não escapa dos afetos. A intervenção do profissional causa algo no usuário, afeta-o. As histórias, acompanhadas das queixas dos usuários, também afetam o profissional.

Afeto (do latim affectus ou adfectus) é um conceito, em filosofia, amplamente utilizado por Benedictus de Spinoza, o qual designa um estado da alma ou um sentimento. Spinoza (2013) concebe o afeto como mudança, modificação ou afecção do corpo e da mente. Tais afecções podem aumentar ou diminuir, estimular ou refrear a potência de agir desse corpo. Quando somos nós a causa dessas afecções, o afeto é compreendido como ação. Quando o outro é a causa, denomina-se paixão. Então, pode-se pensar que, quando o profissional causa no usuário algo bom ou 'nem tão bom assim', ele está agindo, afetando o corpo, a vida do outro, do usuário. Os sentimentos despertados em mim, no profissional, ocasionados pelo encontro com o outro, são da ordem das paixões. Ação e paixão nessa troca de olhares, escapando da unilateralidade.

Dois postulados de Spinoza (2013) ainda são fundamentais para se pensar na questão do acolhimento. O primeiro é que o corpo humano pode ser afetado de diversas formas, tendo sua potência de agir aumentada ou diminuída. Outras tantas formas de afetação do corpo não fazem uma coisa nem outra, e a potência de agir continua a mesma. Aqui, pode-se pensar nos mais variados sentimentos que aumentam ou diminuem a potência de agir.

No caso do encontro entre profissional e usuário, é possível entender que a potência de agir de ambos é a co-construção do Projeto Terapêutico Singular (PTS) e do engajamento no tratamento. Cabe ressaltar que o PTS pode ser concebido como

um conjunto de propostas de condutas terapêuticas articuladas, para um sujeito individual ou coletivo, resultado da discussão coletiva de uma equipe interdisciplinar, com apoio matricial se necessário. (BRASIL, 2007, P. 40).

No decorrer dos encontros e da construção e da reconstrução do PTS, quanto mais afetos positivos forem sentidos, maior a potência de agir, melhor a relação terapêutica, maior a motivação, mais produção de saúde. O segundo postulado é o de que "o corpo humano pode sofrer muitas mudanças, sem deixar, entretanto, de preservar as impressões ou os traços dos objetos" (SPINOZA, 2013, P. 99), mantendo as mesmas imagens das coisas. Aqui, interessam, particularmente, as representações sociais sobre drogas. Essas representações 'fazem' determinadas coisas, elas podem contribuir em processos de exclusão ou estigmatização, por exemplo. Dessa maneira, um profissional pode ser afetado cotidianamente pelos encontros com os usuários, mas continuar acreditando que eles são potenciais criminosos.

Essa circulação ou esse fluxo de afetos é tema de discussão em uma das cartilhas da Política 
Nacional de Humanização (PNH) - também conhecida como HumanizaSUS, que emergiu como política pública visando ao fortalecimento do Sistema Único de Saúde (SUS), em 2003, em pleno processo de avaliação, que envolveu atores implicados e engajados na construção de um sistema público de saúde universal e igualitário (BRASIL, 2007; PASCHE; PASSOS, 2010). Em um trecho, a cartilha chama a atenção dos profissionais para que eles reconheçam esse fluxo de afetos como uma maneira de melhorar os processos de saúde:

É necessário aprender a prestar atenção nesses fluxos de afetos para melhor compreender-se e compreender o outro, e poder ajudar a pessoa doente a ganhar mais autonomia e lidar com a doença de modo proveitoso para ela. (BRASIL, 2007, P. 18).

Nesse processo, portanto, a constituição e o trabalho da equipe de referência são essenciais,

porque os fluxos de afetos de cada membro da equipe com o usuário e familiares são diferentes, permitindo que as possibilidades de ajudar o sujeito doente sejam maiores. Sem esquecer que, dentro da própria equipe estas transferências também acontecem. (BRASIL, 2007, P. 18).

Se a atividade do acolhimento for bem desempenhada pelos profissionais, o acolher desdobra-se em verbos como 'garantir' e 'ampliar' o acesso, bem como 'organizar' ou 'reorganizar' os processos de trabalho. Dessa forma, o acolhimento é concebido, também, como um 'dispositivo de garantia e/ou ampliação do acesso' dos usuários aos serviços da Raps. Acolher é garantir o acesso, vinculado aos princípios da universalidade e da equidade do SUS. Com o aprofundamento e a ampliação das ações de matriciamento e educação permanente em saúde, os Caps $\mathrm{AD}$, por exemplo, garantem não apenas o acesso dos usuários ao próprio Caps, mas um acompanhamento ou uma continuidade do cuidado ao longo de uma linha de cuidado, que vai da atenção primária em saúde à atenção hospitalar, incluindo aí os serviços substitutivos e especializados. $\mathrm{Na}$ busca da superação do modelo ambulatorial, o Caps se 'desencapsula' e consegue perceber o acolhimento para fora de suas próprias paredes, que 'protegem' profissionais e usuários das perigosas andanças pelas malhas finais e relacionais tecidas na rede. Se o acolhimento é atividade de um serviço específico, o usuário pode cair nos buracos dessa rede.

Com as equipes do Caps $\mathrm{AD}$, do $\mathrm{CnR}$ e com os demais profissionais que representavam seus serviços nos Fóruns da Raps, foi aprendido que a atividade do acolhimento se faz em rede, caso contrário, perdem-se os usuários em um fluxo interminável de encaminhamentos. Por isso, o acolhimento também funciona como um 'dispositivo (re)organizador dos processos de trabalho', sendo experimentado em diversas modalidades. Acompanhou-se nas trajetórias coletivas dos serviços aqui observados que a atividade do acolhimento vai sendo remodelada a partir das reorganizações dos serviços e que ela também vai reformulando as práticas de acolhimento. "Ser porta aberta" (Zuleika J.), como é o caso do Caps AD e do CnR, acompanhados nesta pesquisa, implica uma determinada forma de acolher: "acolhe-se tudo, o cara alcoolizado, em crise, sem horário agendado e sem preconceitos" (Sílvia L.).

Mas 'ser porta aberta' faz pensar na inclusão de uma terceira função das práticas de acolhimento: quando garante e amplia o acesso e quando dispara processos de reorganização dos processos de trabalho, o acolhimento, como efeito, é 'produto e produtor de uma desestabilização da noção naturalizada de que a rede é apenas a distribuição e a implementação de pontos/dispositivos de atenção em um determinado território'. No caso do Caps AD, vivencia-se a dificuldade de superar o modelo ambulatorial, não apenas pelas intermináveis tentativas de implantar o Centro de Atenção Diária (CAD) e por resistências de alguns profissionais 
da equipe, mas pelos impasses vividos na articulação com os demais pontos da rede, com a atenção básica e na própria relação tensa com a gestão. No CnR, acompanhou-se uma denúncia radical, não apenas do número insuficiente de dispositivos de atenção na região centro de Porto Alegre, mas da forma como funciona a rede, de como a rede não acolhe o "pobre, feio e sujo" (Sílvia L.). Essa desestabilização ou esse estranhamento de uma noção consolidada de rede só foi possível a partir da vivência de práticas de acolhimento desassossegadoras, de práticas em que se encontra o outro e se percebe o quanto "não estamos dando conta desse sujeito" (Nise S.). Esse encontro, dessa maneira, faz do 'acolhimento uma postura ou tecnologia do cuidado', tecnologia leve, relacional (MERHY, 1999; FRANCO; MERHY, 2013; BRASIL, 2011; NEVES; HECKERT, 2010), "bidirecional” (Franco B.), através da qual profissionais e usuários afetam e são afetados.

O acolhimento, portanto, 'possibilita (ou torna-se possível através de) um encontro de saberes' entre profissionais e profissionais-gestores, entre profissionais e usuários, entre profissionais-gestores e usuários. Inscrito em um regime de alteridade (ARRUDA, 1998; JOVCHELOVITCH, 2008A; 2008B) e de afetabilidade (TEIXEIRA, 2003, 2004; SPINOZA, 2013; NEVES; HECKERT, 2010; FRANCO; MERHY, 2013), O acolhimento se transforma em um encontro dialógico (JOVCHELOVITCH, 2008A, 2008B), sempre polifásico (JOVCHELOVITCH, 2008A, 2008B; ARRUDA, 2011). Polifasia de saberes e afetos.

O acolhimento, nesse sentido, é também 'um encontro de saberes', duas histórias, duas trajetórias que se encontram dentro de um serviço. Cada um dos atores envolvidos traz consigo sua bagagem, seus saberes, seus afetos. Através das andanças pela rede e dos encontros com os profissionais e usuários, percebe-se que há um grande esforço dos profissionais em transformar esses momentos em encontros dialógicos, através dos quais se reconhece o outro como interlocutor legítimo (JOVCHELOVITCH, 2008A, 2008B), buscando ir além de um acolhimento inicial como uma atividade técnico-especializada e promovendo tentativas de se fazer um acolhimento-dialogado em uma rede de conversações (TEIXEIRA, 2003, 2004).

De um lado, profissionais com diferentes formações acadêmicas, diferentes especialidades, experiências em locais diversos de trabalho, diferentes visões de mundo e representações sobre o que é o uso e o usuário de drogas, o morador de rua. Profissionais com diferentes posturas, histórias, trajetórias, desejos. Mesmo estando no mesmo local de trabalho, estão e ocupam diferentes lugares diante de seus colegas e dos usuários. De outro lado, usuários com histórias, contextos, trajetórias e com diferentes formas de se relacionar com as drogas, com as pessoas, de diferentes modos de ser e estar no mundo, com o outro ou de forma mais solitária. Quando o eu e o outro se encontram, quando diferentes mundos se encontram, tem-se apenas o imprevisível e a busca do retorno da capacidade de prometer e de se comprometer com o outro.

Esses profissionais e usuários se encontram cotidianamente em serviços situados em um determinado território, com características sociais e históricas distintas, que respondem a uma determinada gerência distrital, a uma determinada área técnica, com gestores com estilos diversos de 'gerir' desde formas mais democráticas até formas mais autoritárias. Na base de todas essas diferenças, o acolhimento é o efeito de uma construção de algo comum, de uma zona de comunidade, como diria Teixeira $(2003,2004)$. A construção do comum é, ao mesmo tempo, causa e efeito do sentimento de confiança.

Conforme relatou Herbert S. (usuário do Caps AD) em sua entrevista, os usuários "sentem-se acolhidos quando são reconhecidos como pessoas", quando são vistos como pessoas "dignas de confiança" - para além de sua doença e de suas condições de vida. Alegria, esperança, conforto e, também, desânimo, tristeza e frustração compõem esse complexo fluxo de afetos. Os profissionais, 
por sua vez, sentem-se, igualmente, frustrados quando se deparam com situações difíceis, quando o usuário não se vincula ao serviço. Cansaço, exaustão, mas, também, alegria em encontrar com as pessoas, e não com os 'doentes'. Percebem, às vezes, a duras penas, que "não é possível acolher sem ser acolhido" (Grupo de Discussão Caps AD), pois isso é o espaço intercessor (FRANCO; MERHY, 2013), o comum, que tem como efeito a confiança. $\mathrm{O}$ acolhimento, portanto, é produto e produtor de um turbilhão de afetos e sentimentos, sentido por aqueles que estão "no olho do furacão' (FRANCO; MERHY, 2013). Por trás de toda e qualquer definição, 'o acolhimento é sempre um sentimento ou uma sensação', por mais protocolar que possa parecer a ação.

Ser reconhecido como pessoa é sentir-se acolhido. Escutou-se de vários usuários, tanto do Caps $\mathrm{AD}$ quanto do $\mathrm{CnR}$, que foi nesses serviços que eles se sentiram reconhecidos como pessoas. E o profissional deve gostar do que faz, sentir alegria quando consegue reconhecer esse usuário de droga ou morador de rua como pessoa. Esse debate leva ao âmbito das paixões, dos sentimentos dos profissionais quando estão acolhendo os usuários dos serviços. Assim como a potência de agir dos usuários pode ser aumentada ou diminuída, dependendo de como serão recebidos, a dos profissionais também. Conforme mostra uma das profissionais presentes na discussão:

na saúde mental, tem outra energia, e aí tu vê o quanto aquele encontro, nessa troca, quanto a gente se doa muito mais para o outro, porque a gente percebe a carência de energia que ele está, carência que ele está de chama de vida, digamos assim. Então, por vezes, na época que eu era mais assistência, eu acolhia dez pessoas numa manhã e eu sentia 'nossa eu preciso sentar, eu preciso dar uma respirada', porque essa energia me consumiu bastante, e aí eu vejo o quanto a gente, os profissionais, esquecem um pouco de se trabalhar também, porque a troca com o outro, tu vai trocar com o outro e tu tem que estar bem nessa troca, nessa energia bacana, porque quem está chegando está precisando muito dessa troca. (Grupo de Discussão Fórum AD).

Outra profissional complementa que " $a$ gente é ser humano e tem limite também de desgaste físico, emocional, mas eu acho que vale muito a pena" (Grupo de Discussão Fórum $\mathrm{AD})$. Por isso, a importância de o profissional “também se trabalhar", de pensar no cuidado para o cuidador. Essa diminuição de energia pode ser entendida como uma diminuição na potência de agir, usando o termo de Spinoza (2013). Essa constatação é fundamental, pois coloca o acolhimento num plano de trocas. Se o profissional quer cuidar, ele precisa ser cuidado e buscar formas de autocuidado - "tu vai trocar com o outro e tu tem que estar bem nessa troca" (Grupo de Discussão CnR). Mas, além dos desgastes físico e emocional, ou de energia, como pontuou a profissional, sentimentos como compaixão, raiva e impotência também são experimentados pelos profissionais.

Tendo como base as concepções de acolhimento discutidas acima, foi proposto um esquema que sintetiza esse caráter polissêmico e polifásico do acolhimento nos serviços da Raps. Tomando como referência o esquema proposto por Teixeira (2004), propõem-se alguns elementos que complementem a sua definição (figura 1). Conforme já foi visto, cada sujeito traz consigo sua bagagem simbólica, suas crenças, sua história, seus afetos, seus saberes, suas representações. Como referem Macedo e Machado (2016), ao analisar a economia moral que permeia as práticas dos/as profissionais de saúde com relação ao cuidado a gestantes que usam crack,

os/as profissionais se inserem em lógicas mais amplas que conformam e influenciam suas escolhas, o que fazem, ou não, em suas práticas de saúde. (P. 43).

Ou seja, as concepções sobre drogas que circulam nos serviços de saúde sustentam determinadas práticas de cuidado (MACEDO; MACHADO, 2016). 
Figura 1. As práticas de acolhimento e seu caráter polifásico

Fluxo de Afetos e Sentimentos:

Alegria, 'sentir-se reconhecido como pessoa', 'sentir-se acolhido', tristeza, exaustão, frustração, conforto etc. 'é impossível acolher sem ser acolhido'

Usuários com histórias, contextos, trajetórias e com diferentes formas de se relacionar com as drogas, com as pessoas, de diferentes modos de ser e estar no mundo, com o outro ou de forma mais solitária. Trajetórias difíceis, pobreza, discriminação, exclusão social, mas, também, com construção de redes de sociabilidades e de cuidado.
Diferentes formações acadêmicas, especialidades, posturas, histórias de vida, experiências em locais diversos de trabalho, diferentes visões de mundo e representações sobre o que é o uso e o usuário de drogas, o morador de rua. Relações com a gestão, gerência distrital e em determinado território.

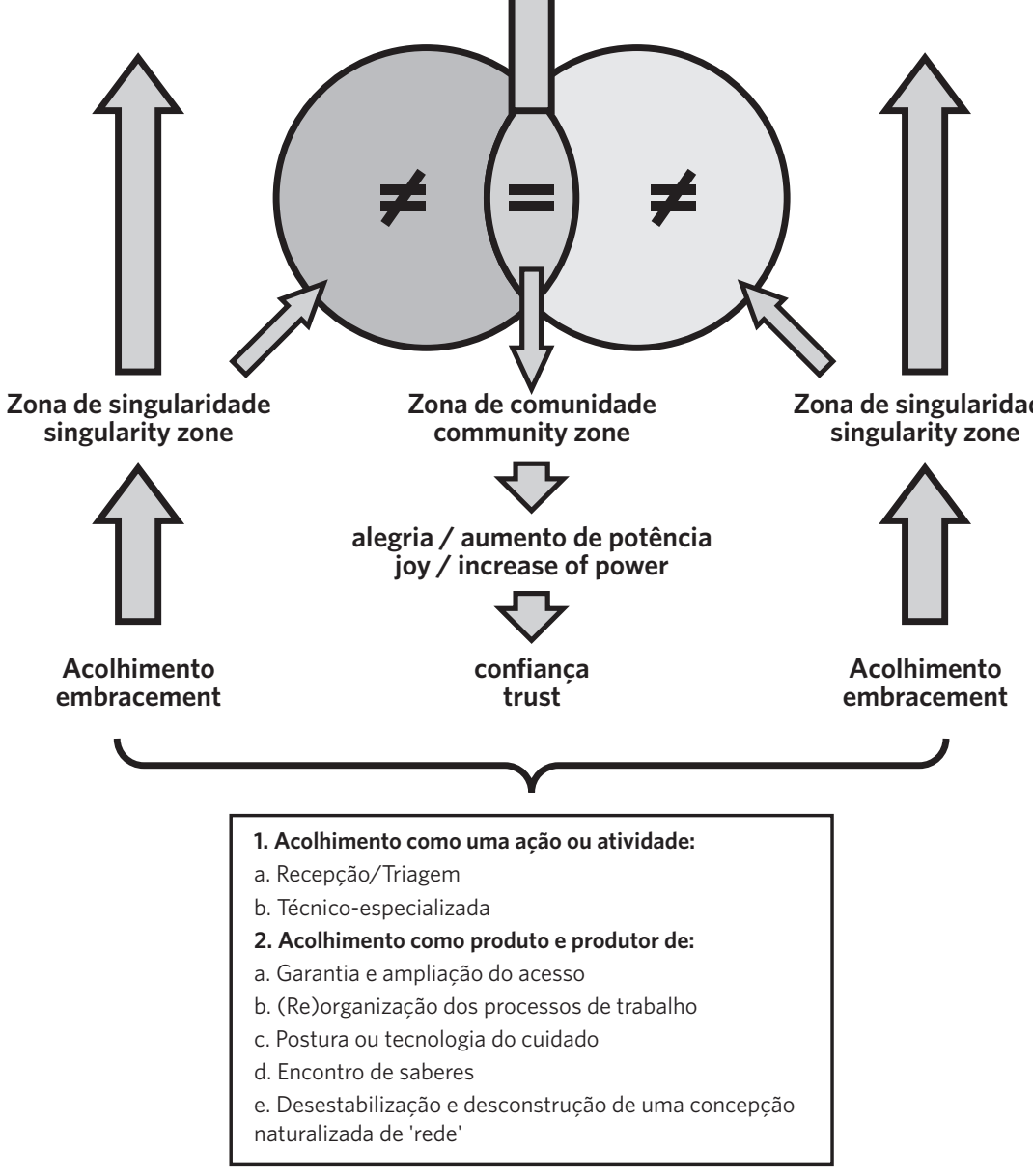

Fonte: Esquema elaborado pelo autor a partir do diagrama apresentado por Teixeira (2004).

Muitos dos profissionais e usuários que participaram desta pesquisa trazem consigo essas representações. O que mais se viu foi a representação do usuário de drogas como um doente e como um criminoso. São representações construídas socialmente, na interação com seus grupos, familiares, amigos e inseridas em um contexto histórico-cultural. Nos encontros cotidianos que ocorrem nos serviços, esses saberes vão, aos poucos, transformando-se. Essa transformação, que produz e é produzida pelo desassossego diante do outro, é sentida e narrada tanto pelos profissionais quanto pelos usuários. 
Dessa maneira, pode-se afirmar que os encontros de saberes entre profissionais e usuários, quando dialógicos, transformam as práticas de acolhimento. E o contrário também parece pertinente, ou seja, à medida que as equipes reinventam e reconstroem suas noções e práticas de acolhimento, os saberes de usuários e profissionais vão se transformando.

Ao acompanhar as práticas de acolhimento no cotidiano dos serviços, foi possível observar a prática concreta, os encontros concretos dos sujeitos. Esse encontro entre dois sujeitos, como Teixeira (2004) buscou vislumbrar através do diagrama, vai se complexificando se for imaginada uma continuação desse mesmo esquema. Do lado do círculo que representa o usuário, podem-se imaginar vários outros círculos fazendo intersecção, produzindo espaços intercessores com os usuários, como outras pessoas, familiares, amigos, outros profissionais, outros serviços de saúde e assistência social. Do mesmo modo, podem-se imaginar outras intercessões com os profissionais, suas famílias, outros serviços, os gestores, a secretaria de saúde. Ao multiplicar por ' $n$ ' os círculos e suas intercessões, conseguiu-se compreender por que o acolhimento pode ser também concebido como uma rede de conversações. São múltiplas relações e encontros.

Spinoza (2013) diz que a lei da vida é a lei dos encontros. $\mathrm{O}$ acolhimento vai se produzindo, então, no plano dos encontros, nos fluxos de afetos construídos a cada encontro e através deles. Se a lei da vida é a lei dos encontros,

a vida é pensada como potência que se ativa entre os sujeitos, nas relações e vínculos que constroem (e os constroem); como potência de afetar e ser afetado. (NEVES; HECKERT, 2010, P. 162).

É o que os profissionais disseram no Grupo de Discussão do Fórum $\mathrm{AD}$ - a alegria, quando se encontra o sujeito que está por trás da doença, que está além daquela trajetória de sofrimento. Por isso, ainda conforme Neves e Heckert (2010, P. 153), a construção de práticas de acolhimento que possam fazer da existência uma arte de viver sustenta-se no cultivo de uma prática ética em que o cuidado consigo, com o outro e com o mundo, se faz quando cuidamos da dimensão coletiva e relacional de nossa existência.

O acolhimento como uma postura ética, como uma tecnologia do cuidado.

\section{Considerações finais}

Neste artigo, buscou-se sintetizar e refletir sobre as concepções e práticas de acolhimento vivenciadas cotidianamente nos serviços da Raps da cidade de Porto Alegre (RS). Viu-se, brevemente, que o acolhimento é um conceito e uma prática polifásica, polissêmica. Diante de tantas definições, o acolhimento, enquanto encontro, destaca-se. Um encontro entre usuários e profissionais, encontros que desassossegam, encontros que produzem (ou buscam produzir) o comum. É justamente nos e através dos encontros que se depara com outras pistas ou desafios para a construção do comum nas políticas sobre drogas, buscando a superação da individualização do fracasso.

Com as equipes da Área Técnica de Saúde Mental, do Caps AD, do CnR e demais profissionais Raps que participaram dos Fóruns AD, de um modo geral, foi possível aprender e aprofundar as noções e práticas de acolhimento. Nos três contextos observados (AT, Caps $A D$ e CnR), vislumbrou-se a noção de acolhimento como uma ação ou atividade técnico-especializada, um dispositivo de garantia e/ou ampliação do acesso, um dispositivo de (re)organização dos processos de trabalho e como uma postura e/ ou tecnologia do cuidado. Acredita-se que este trabalho traz novos elementos para se pensar no acolhimento como um encontro de saberes entre profissionais e usuários, saberes que vão se transformando no encontro com o outro. Neste sentido, o 
acolhimento possibilita (ou torna-se possível através de) um encontro de saberes, entre profissionais e profissionais-gestores, entre profissionais e usuários, entre profissionais-gestores e usuários.

Inscrito em um regime de alteridade e de afetabilidade, o acolhimento se transforma em um encontro dialógico, sempre polifásico e marcado por tensões. Além disso, propõe-se que, como efeito, o acolhimento é produto e produtor de uma desestabilização da noção naturalizada de que a rede é apenas a distribuição e a implementação de pontos/ dispositivos de atenção em um determinado território. $\mathrm{O}$ acolhimento como um efeito de 'sentir-se acolhido' também provoca os mais variados sentimentos: alegria, confiança, tristeza, cansaço, impotência. Nesse fluxo de afetos, o acolhimento, portanto, é uma conquista, na árdua tarefa de construção do comum nos serviços de saúde e nos encontros. Para isso, frisa-se que é impossível acolher sem ser acolhido.

Quando se superam as práticas de colhimento, encolhimento e recolhimento, pautadas no fracasso individual como tecnologia de subjetivação, passa-se a refletir e propor práticas de acolhimento a pessoas que usam drogas. Acolher essa pessoa, tendo como pressuposto a necessidade de construção do comum, significa, portanto, subverter a lógica da individualização do fracasso, culpando o sujeito pela doença que adquiriu apenas por hábitos ou predisposições individuais (colhimento); desnaturalizar as representações e os saberes que reduzem o sujeito à doença, que reduzem a dependência à química e a intervenções que se propõem a curar a doença, e não tratar do sujeito (encolhimento); e desconstruir a noção amplamente difundida de que é o usuário de crack ou o morador de rua que empobrece e desvaloriza determinados espaços públicos, de que essas pessoas estão lá porque já eram espaços abandonados pelo Estado e que não é possível homogeneizar esse grupo, já que cada pessoa e cada subgrupo, nas ruas, estabelecem relações singulares com as drogas (recolhimento).

É importante frisar que o recolhimento parece ser o efeito da combinação do colhimento e do encolhimento. Nesse sentido, reafirma-se que o acolhimento é uma diretriz ética - porque opera no encontro com o outro, na relação com a alteridade; estética - os profissionais inventam, cotidianamente, novas formas de acolher e, também, de serem acolhidos; e política, porque reafirma o compromisso coletivo com o cuidado do outro, o compromisso de construção do comum nas políticas de saúde. O acolhimento a pessoas que sofrem com o uso ou o abuso de drogas, portanto, envolve acolher e ser acolhido, disposição para o encontro, fluxo intenso de afetos, transformação de saberes e preconceitos, transformação de si e do outro.

\section{Colaboradores}

Todos os autores deste manuscrito contribuíram substancialmente para a concepção e o planejamento ou para a análise e a interpretação dos dados, bem como para a elaboração do rascunho ou da revisão crítica do conteúdo e para a aprovação da versão final do manuscrito.

\section{Agradecimentos}

Agradecemos a todas as pessoas que tornaram possível a escrita deste trabalho, em especial, aos nossos heterônimos-interlocutores, que nos acolheram e permitiram que os encontros e os desassossegos fossem possíveis. 


\section{Referências}

ARENDT, H. A condição humana. 11. ed. Rio de Janeiro Forense Universitária, 2010.

ARRUDA, A. O ambiente natural e seus habitantes no imaginário brasileiro. In: (Org.). Representando a alteridade. Petrópolis, RJ: Vozes, 1998. p. 17-46.

Representações sociais: dinâmicas e redes. In: ALMEIDA, A. M. O.; SANTOS, M. F. S.; TRINDADE, Z. A. Teoria das representações sociais: 50 anos. Brasília, DF: Technopolitik, 2011. p. 335-369.

BARROS, M. E. B.; PIMENTEL, E. H. C. Políticas públicas e a construção do comum: interrogando práticas PSI. Revista Polis e Psique, Porto Alegre, v. 2, n. 2, p. 3-22, 2012.

BRASIL. Ministério da Saúde. Secretaria de Atenção à Saúde. Departamento de Atenção Básica. Acolhimento à demanda espontânea. Brasília, DF: Ministério da Saúde, 2011.

Ministério da Saúde. Secretaria de Atenção à Saúde. Núcleo Técnico da Política Nacional de Humanização. Acolhimento nas práticas de produção de saúde. 2 ed. Brasília, DF: Ministério da Saúde, 2006.

Ministério da Saúde. Secretaria de Atenção à Saúde. Núcleo Técnico da Política Nacional de Humanização. Clínica ampliada,equipe de referência e projeto terapêtico singular. 2. ed. Brasília, DF: Ministério da Saúde, 2007.

FRANCO, T. B.; BUENO, W. S.; MERHY, E. E. O acolhimento e os processos de trabalho em saúde: o caso de Betim, Minas Gerais, Brasil. Cadernos de Saúde Pública, Rio de Janeiro, v. 15, n. 2, p. 345-353, 1999. Disponível em: <http://www.scielosp.org/pdf/csp/v15n2/0319>. Acesso em: 5 dez. 2016.

FRANCO, T. B.; FRANCO, C. M. Acolhimento com classificação de risco e a micropolítica do trabalho em saúde: a experiência de Silva Jardim/Rio de Janeiro. Revista APS, Juiz de Fora, v. 15, n. 2, p. 227-233, 2012. Disponível em: <https://aps.ufjf.emnuvens.com.br/aps/ article/view/1516>. Acesso em: 5 dez. 2016.

FRANCO, T. B.; MERHY, E. E. (Org.). Trabalho, produção do cuidado e subjetividade em saúde: textos reunidos. São Paulo: Hucitec, 2013.

JOVCHELOVITCH, S. Os contextos do saber: representações, comunidade e cultura. Petrópolis, RJ: Vozes, 2008a.

The rehabilitation of common sense: social representations, science and cognitive polyphasia. Journal for the Theory of Social Behaviour, Nova Iorque, v. 38, n. 4 , p. $43-448,2008$ b.

MACEDO, F. S.; MACHADO, P. S. Economia Moral e Modelos de Atenção no cuidado com gestantes que usam crack. Saúde em Debate, Rio de Janeiro, v. 40, n. 109, p. 34-46, 2016.

MERHY, E. E. O ato de governar as tensões constitutivas do agir em saúde como desafio permanente de algumas estratégias gerenciais. Ciência \&́ Saúde Coletiva, Rio de Janeiro, v. 4, n. 2, p. 305-314, 1999.

NEVES, C. A. B.; HECKERT, A. L. C. Micropolítica do processo de acolhimento em saúde. Estudos e Pesquisas em Psicologia, Rio de Janeiro, ano 10, n.1, p.151-168, 2010.

PASCHE, D. F.; PASSOS, E. Inclusão como método de apoio para a produção de mudanças na saúde - aposta da Política de Humanização da Saúde. Saúde em Debate, Rio de Janeiro, v. 34, n. 86, p. 423-432, 2010.

ROMANINI, M.; DETONI, P. P. A culpabilização como efeito do modo indivíduo de subjetivação nas políticas sociais. Revista Polis e Psique, Porto Alegre, v. 4, n. 2, p. 206-229, 2014

ROMANINI, M.; ROSO, A. Midiatização da cultura, criminalização e patologização dos usuários de crack: discursos e políticas. Temas em Psicologia, Ribeirão Preto, v. 21, n. 2, p. 483-497, 2013. 
SCHMIDT, M. B.; FIGUEIREDO, A. C. Acesso, acolhimento e acompanhamento: três desafios para o cotidiano da clínica em saúde mental. Revista Latinoamericana de Psicopatologia Fundamental, São Paulo, v. 12, n. 1, p. 130-140, mar. 2009.

SOUZA, T. P.; CARVALHO, S. R. Reduzindo danos e ampliando a clínica: desafios para a garantia do acesso universal e confrontos com a internação compulsória. Polis e Psique, Porto Alegre, v. 2, n. temático, p. 37-58, 2012.

SPINOZA, B. Ética. 2. ed. Belo Horizonte: Autêntica, 2013.

TEIXEIRA, R. R. As redes de trabalho afetivo e a contribuição da saúde para a emergência de uma outra concepção de público. In: RESEARCH CONFERENCE ON RETHINKING THE PUBLIC IN PUBLIC
HEALTH: NEOLIBERALISM, STRUCTURAL VIOLENCE AND EPIDEMICS OF INEQUALITY IN

LATIN AMERICA. 2004. San Diego. Anais... San Diego: Universidade da Califórnia, 2004. Disponível em: <http://www.corposem.org/rizoma/redeafetiva.html>. Acesso em: 20 set. 2014.

O acolhimento num serviço de saúde entendido como uma rede de conversações. p. 89-111. In: PINHEIRO, R.; MATTOS, R. A. (Org.). Construção da integralidade: cotidiano, saberes e práticas em saúde. Rio de Janeiro: IMS-UERJ, ABRASCO, 2003.

Recebido para publicação em dezembro de 2016

Versão final em maio de 2017

Conflito de interesses: inexistente

Suporte financeiro: bolsa de doutorado Capes 